\title{
Minimally invasive mitral valve surgery
}

\author{
Yasir Abu-Omar ${ }^{1 \#}$, Ibrahim T. Fazmin ${ }^{2 \#}$, Jason M. Ali ${ }^{2}$, Marc P. Pelletier ${ }^{1}$ \\ ${ }^{1}$ University Hospitals Cleveland Medical Center, Cleveland, OH, USA; ${ }^{2}$ Department of Cardiothoracic Surgery, Royal Papworth Hospital, \\ Cambridge, UK \\ Contributions: (I) Conception and design: All authors; (II) Administrative support: All authors; (III) Provision of study materials or patients: All \\ authors; (IV) Collection and assembly of data: All authors; (V) Data analysis and interpretation: All authors; (VI) Manuscript writing: All authors; (VII) \\ Final approval of manuscript: All authors. \\ \#These authors contributed equally to this work. \\ Correspondence to: Jason M. Ali, PhD. Department of Cardiothoracic Surgery, Royal Papworth Hospital, Cambridge, CB2 0AY, UK. Email: ja297@cam.ac.uk.
}

\begin{abstract}
There is considerable interest and demand in the application of minimally invasive techniques in cardiac surgery driven by multiple factors including patient cosmesis and satisfaction, reduction of surgical trauma and the development of specialized instrumentation that allows these procedures to be performed safely. Minimally invasive mitral valve surgery (MIMVS) has been conducted for more than 25 years and has been shown to offer multiple benefits including better cosmetic results, enhanced post-operative recovery, improved patient satisfaction and most importantly, equivalent clinical outcomes with regards to quality and safety when compared to the standard sternotomy approach. MIMVS may be particularly beneficial in certain subgroups of patients, for example patients undergoing redo mitral valve surgery. In this article, we discuss patient selection criteria for MIMVS, the merits and drawbacks of MIMVS relative to conventional sternotomy approaches, and detail procedural aspects including anaesthetic management, intraoperative technique, and important considerations in myocardial protection and cardiopulmonary bypass (CPB). When considering developing a MIMVS programme, as for any new technique, a team approach to the introduction of the programme is essential. Although it is clear that patient selection is important, particularly early in a surgical programme, with experience complex repairs can be performed through a minimally invasive approach with excellent outcomes.
\end{abstract}

Keywords: Mini-thoracotomy; minimally invasive surgery; mini-mitral surgery

Submitted Jun 02, 2020. Accepted for publication Aug 24, 2020.

doi: $10.21037 /$ jtd-20-2114

View this article at: http://dx.doi.org/10.21037/jtd-20-2114

\section{Introduction}

There has been an increasing interest in minimally invasive approaches to cardiac surgical procedures over the last 2 decades. This has been driven by multiple factors such as patient cosmesis and satisfaction, reduction of surgical trauma and the development of specialized instrumentation that allows these procedures to be performed safely. Unlike other surgical specialties, there are specific challenges and considerations when performing minimally invasive cardiac surgical procedures, especially with regards to cardiopulmonary bypass (CPB) and myocardial protection. These challenges have been tackled for a variety of cardiac lesions, and much success has been achieved for mitral valve pathologies. From the early days of HeartPort technology (1), minimally invasive mitral valve surgery (MIMVS) through a right mini thoracotomy has become well-established and widely practiced around the globe. The history of MIMVS extends from the 1990s when minimally invasive approaches such as the parasternal incision, hemisternal incision and the mini-thoracotomy were first explored by independent groups led by Delos Cosgrove and Lawrence Cohn (2-4). Subsequent developments include the first video-directed repair (5) and replacements $(6,7)$ performed through a mini-thoracotomy, and the first use of aortic endoballoon clamping. More recent developments include the advent 
of stereoscopic three-dimensional video-endoscopy and robotic surgery. As with most innovative procedures, expert proponents report equivalent results with faster patient recovery, reduced morbidity and improved patient satisfaction. However, the procedure does add some technical challenges, and the majority of mitral valve procedures continue to be performed through a full median sternotomy.

In addition to the mini-thoracotomy, alternative minimally invasive approaches to the mitral valve have been reported. A parasternal approach has been described - through a $10 \mathrm{~cm}$ right parasternal incision with excision of the third and fourth costal cartilages $(8,9)$. Although providing good access, patients occasionally suffered with chest wall instability $(8,10)$. Furthermore, the right internal mammary artery was sacrificed $(8,10)$. Others have reported mitral valve surgery through a mini sternotomy with the advantage of easy conversion to full sternotomy if required $(8,9)$. Here, we will focus on the mini-thoracotomy approach to MIMVS, which we feel offers multiple advantages over all other minimally invasive techniques. We present the following article in accordance with the NARRATIVE REVIEW reporting checklist (available at http://dx.doi.org/10.21037/jtd-20-2114).

\section{Patient selection}

Patient selection is critical in mini-thoracotomy $\mathrm{MV}$ surgery. This is especially true in the early stages of program and skill development. Naturally, a surgeon would start with patients with minimal comorbidities and anatomically repairable MV disease (9). Different technical skills must be acquired for minimally invasive surgery compared to a standard approach. These skills are associated with a distinct learning curve-some have suggested an estimated $75-125$ procedures to attain proficiency $(11,12)$. Patients requiring more complex repairs can be considered suitable in more experienced hands $(12,13)$. However, by taking a standardized approach, these skills can easily be acquired and developed.

It is also important to consider factors that make MIMVS more challenging, or potentially increase the risk, and consider these as relative or absolute contraindications (Table 1). Patients with significant comorbidities or impaired cardiac function should be carefully considered — particularly early in a program when it is likely that the procedure will take longer than a standard sternotomy. The patient's size and shape are important considerations. Patients with high
BMI can pose a challenge in achieving effective peripheral $\mathrm{CPB}$ and chest wall deformities can present a significant challenge to achieve the necessary access and exposure (9). Patients who have had previous right sided thoracic surgery or radiotherapy, who may have significant adhesions, should be avoided (9). In view of the cannulation requirements for $\mathrm{CPB}$, it is necessary to assess for the presence of peripheral vascular disease and size of the peripheral vasculature. For this reason, pre-operative evaluation with a contrast CT is often desirable in order to assess aortic atherosclerosis, aneurysms or dissection, and also to provide information with regards to thoracic anatomy (e.g., diaphragm elevation, optimal intercostal access).

Additionally, MIMVS may be a beneficial approach in certain subgroups of patients. MIMVS may have a role in redo mitral valve surgery, with studies reporting ranges of $1-35.6 \%$ of MIMVS being redo procedures (14). This is especially useful when reopening of the sternum is to be avoided, which avoids the risk of damaging cardiac structures, adhesions from prior surgeries and coronary grafts (14). Another attractive niche of patients is those who would be considered "high risk" for conventional surgery. There appears to be acceptable outcomes in these cases (in terms of postoperative recovery and mortality) which includes populations of patients with infective endocarditis, previous cardiac surgery and age $>75$ (15).

\section{Anaesthetic management in minimally invasive MV surgery}

Minimally invasive techniques require additional considerations in terms of anaesthesia, ventilation and monitoring. With a right mini-thoracotomy approach, it is necessary to collapse the right lung in order to access the MV. Various options exist, but a double lumen tube is typically preferred for single-lung ventilation $(8,9)$. Alternatively, an endobronchial blocker could be used to isolate the right lung (9). Recently, some surgeons report MIMVS surgery using a single lumen endotracheal tube $(16,17)$, by placing the patient on bypass earlier, allowing both lungs to be collapsed. Normally, only one arterial line is required, typically in the left arm since the right arm will be tucked. For cases performed with an aortic endoballoon, bilateral radial artery pressure monitoring may be required in order to detect displacement (8). The patient is typically positioned supine, tilted slightly away from the surgeon by elevating the right side, and will have defibrillator pads placed $(8,9,18)$. 
Table 1 Relative contraindications to MIMVS

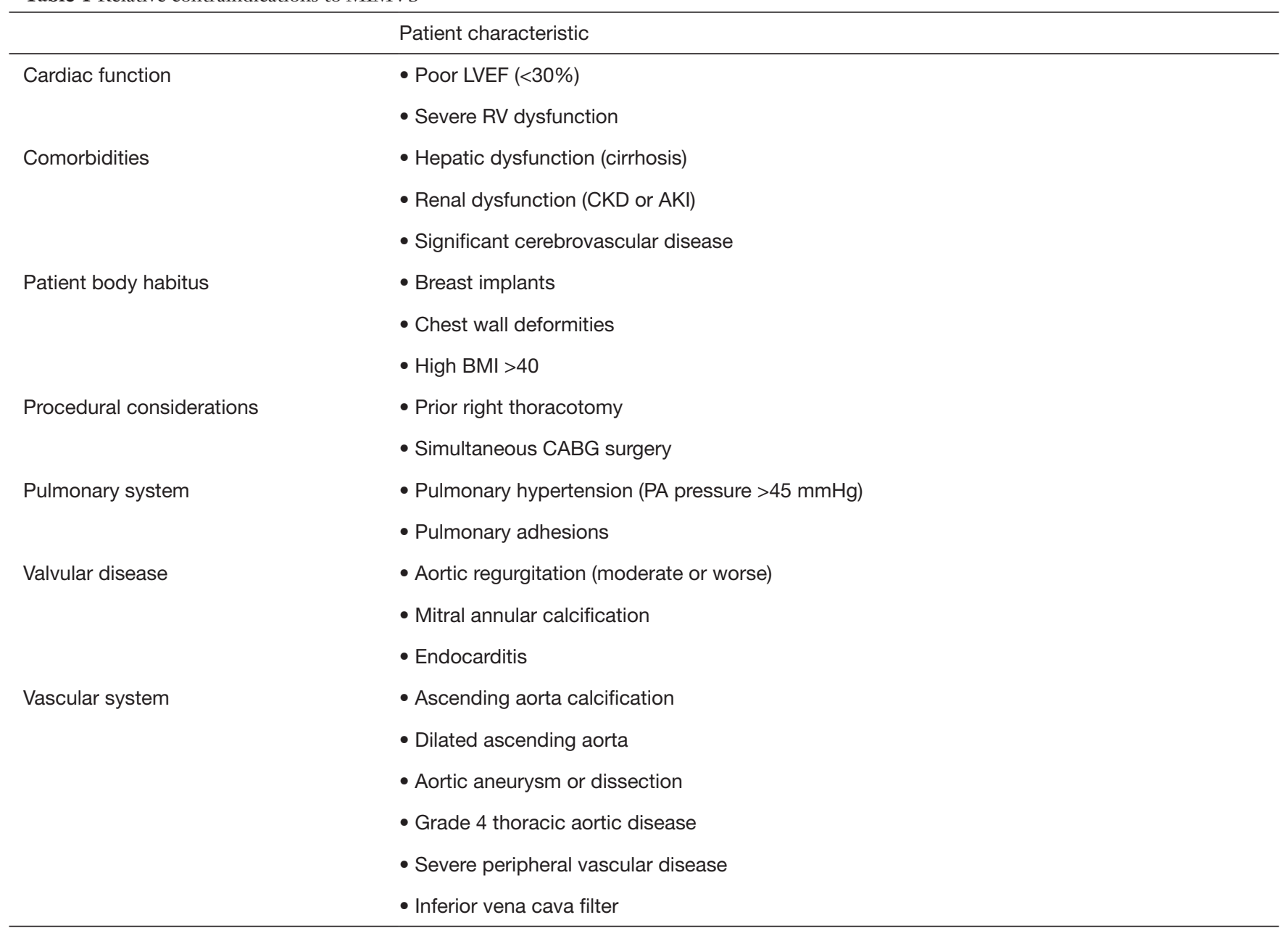

Informed by (9,12). MIMVS, minimally invasive mitral valve surgery; AKI, acute kidney injury; BMI, body mass index; CABG, coronary artery bypass graft; CKD, chronic kidney disease; LVEF, left ventricular ejection fraction; PA, pulmonary artery; RV, right ventricular.

Transoesophageal echocardiography (TOE) is required in nearly all patients, as in conventional surgery, to verify cardiac and valvular function prior to surgery, but also offers additional assessment and guidance specific to MIMVS access and cannulation techniques (Table 2) (9,19-21).

\section{Mini-thoracotomy surgical technique}

The right mini-thoracotomy is the most commonly used approach for MIMVS (8). The $4^{\text {th }}$ intercostal space is entered and a soft tissue retractor with or without a rib spreader are used $(8,9,18)$ (Figures 1,2). A range of additional incisions/ports are introduced depending on surgeons' preference and approach for CPB and myocardial protection.
Pleural adhesions, which may have arisen due to numerous pathologies or prior surgery, may pose difficulties with the right mini thoracotomy approach, but if the adhesions are not extensive, it may be possible to lyse these relatively easily. Through the mini thoracotomy, the pericardium is incised well clear of the phrenic nerve, extending superiorly to expose the ascending aorta and inferiorly to the diaphragm. In case of a high hemidiaphragm, a retraction suture may be placed in the central tendon and retracted inferiorly through one of the ports. Visualisation may be enhanced using a thoracoscope, although many surgeons elect to do this procedure under direct vision $(8,18)$. Once feasibility of the operation is confirmed, the patient is placed on CPB.

It is worth noting that as surgeons become increasingly 
Table 2 Utility of trans-oesophageal echocardiography in MIMVS

\begin{tabular}{ll}
\hline & Purpose of TOE \\
\hline Assessment & - Evaluate biventricular function \\
& - Full assessment of the mitral valve pathology \\
& - Identifying any other valvular pathology \\
- Placement of retrograde cardioplegia cannulae into coronary sinus directly, or indirectly through IJV & Positioning femoral venous catheters \\
& - Positioning PA drainage cannulae \\
& - Placement of an IABP \\
& - Position an aortic endoballoon for internal cross-clamping
\end{tabular}

Informed by (9,19-21). MIMVS, minimally invasive mitral valve surgery; TOE, transoesophageal echocardiography; IJV, internal jugular vein; PA, pulmonary artery; IABP, intra-aortic balloon pump.

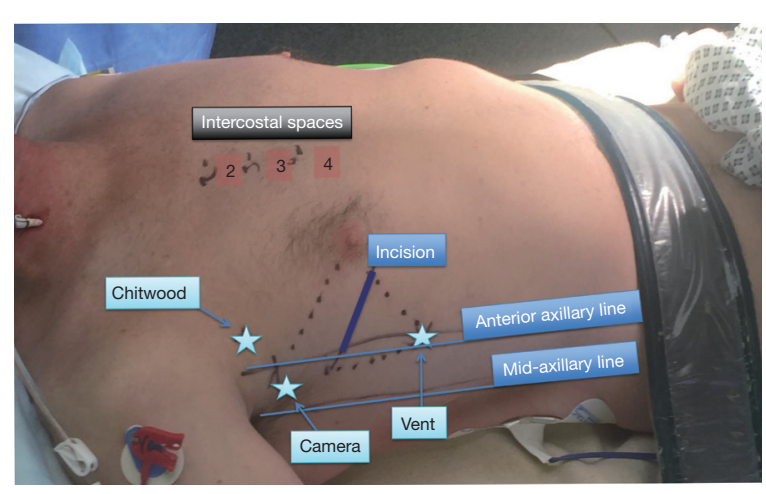

Figure 1 Demonstration of the anatomical landmarks and position of incisions and ports for minimally invasive mitral valve surgery.

experienced at performing this procedure, the advancing of techniques involve less or no rib spreading and increased reliance on video assistance as opposed to direct vision. Additionally, stereoscopic endoscopy allowing for threedimensional vision is an emerging technology which gives surgeons superior depth perception during surgery (22-25). This is being increasingly adopted across many centres worldwide although it sees much more use in robotic surgery. Robotic MIMVS is beyond the scope of the current article and is discussed in another chapter of this article series.

\section{Establishment of CPB}

Before beginning operative work on the mitral valve itself, there are several approaches one may adopt in terms of CPB, aortic cross clamping and myocardial protection (Table 3). Cannulation for CPB in the right thoracotomy approach is

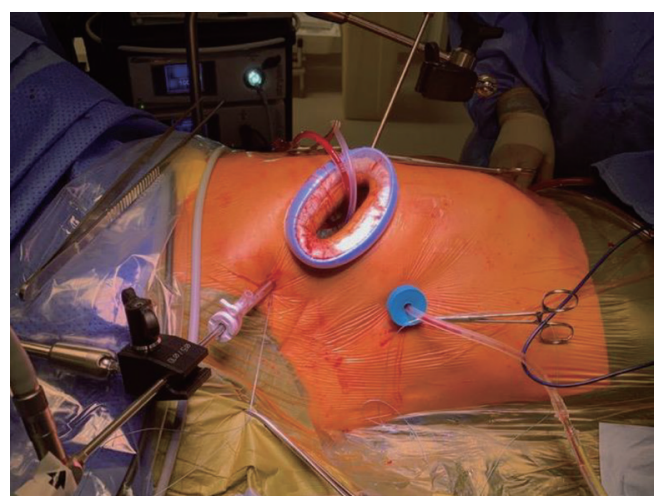

Figure 2 Demonstration of the set-up for minimally invasive mitral valve surgery, with utility port.

complicated by the confined operating space. Different sites of arterial and venous cannulation may be used, with peripheral cannulation being the most common. Arterial access is usually achieved with femoral artery cannulation $(9,18)$. Alternatively, the axillary artery may also be used for cannulation. Venous drainage is typically achieved with a femoral multistage cannula advanced into the SVC under TEE guidance. For some patients, such as those with a high BMI, an additional internal jugular venous cannula may be required to ensure adequate venous drainage (9). One concern with femoral arterial cannulation is the risk of retrograde aortic embolization leading to cerebrovascular accident. This highlights the importance of preoperative vascular assessment. As such, a recently published meta-analysis reports low incidence of neurological events in peripherally cannulated patients undergoing MIMVS (13). Less commonly, some surgeons opt for central cannulation. An 
Table 3 Techniques for bypass, aortic cross clamping and myocardial protection during MIMVS

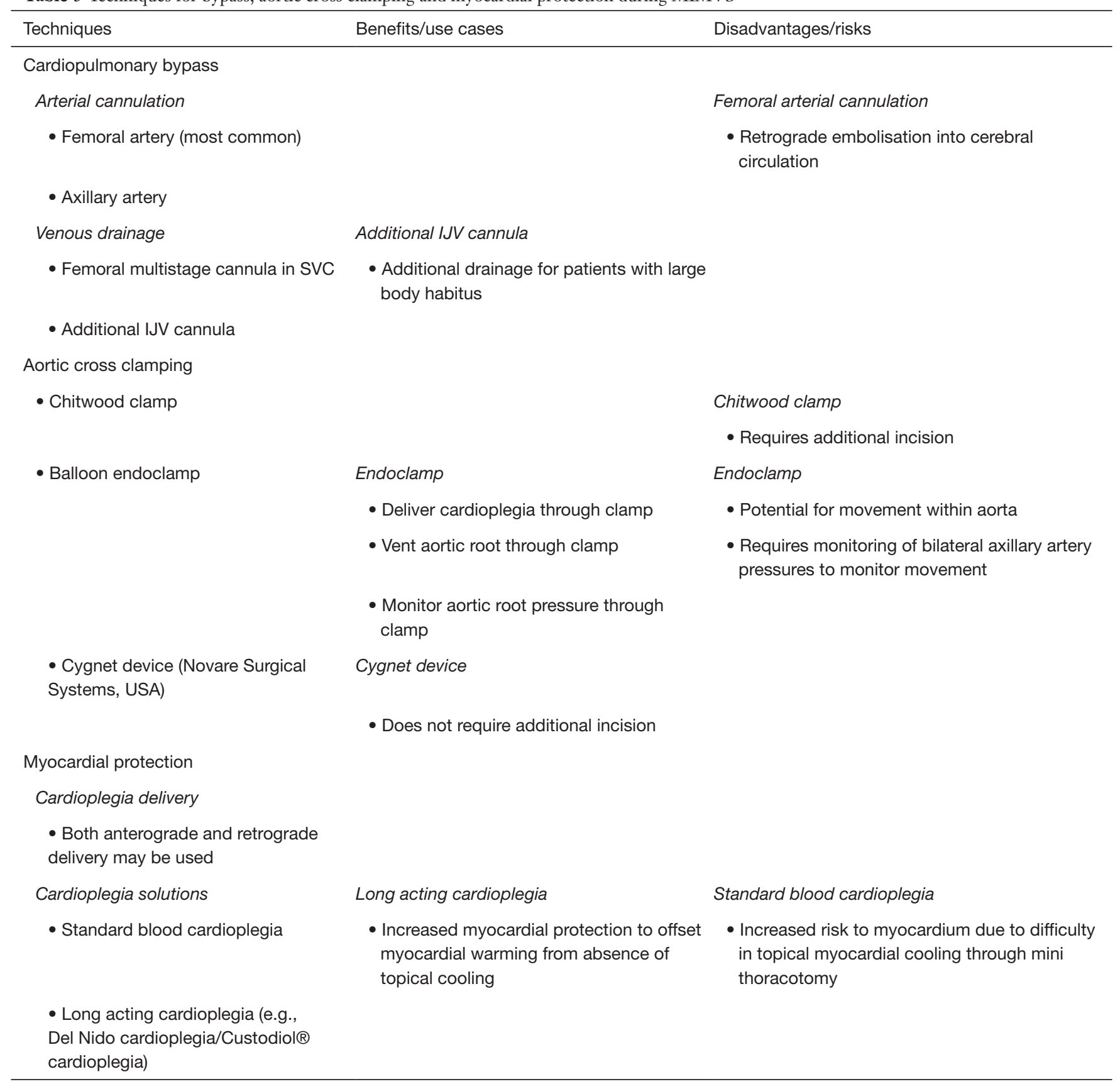

MIMVS, minimally invasive mitral valve surgery; IJV, internal jugular vein.

aortic cannula can be placed directly into the ascending aorta through a small incision over the $2^{\text {nd }}$ intercostal space and a two-stage venous cannula may be placed directly into the right atrium through an incision in the $4^{\text {th }}$ intercostal space $(9,26)$.

\section{Aortic cross clamping}

There are several approaches to aortic cross clamping that may be used. External cross clamping may be achieved by passing a Chitwood clamp directly through either the second or third intercostal space $(6,9,26)$. Alternatively, internal occlusion of the ascending aorta with an internal endoclamp has been successful, under fluoroscopic or TOE guidance, through either the femoral or axillary artery $(9,27,28)$. The endoclamp offers functions in addition to 
clamping which are not offered by the external clamp. These include the ability to deliver cardioplegia, vent the aortic root, and monitor aortic root pressure through the tip of the endoballoon (29). Disadvantages include movement of the endoballoon within the aortic lumen which may not be visible during the procedure, necessitating the use of bilateral axillary pressure monitoring to detect displacement (8). An alternative to both the aortic endoclamp and the external Chitwood clamp is the external Cygnet device (Novare Surgical Systems, USA) which does not require an additional port and can be used through the main operating port (29). In terms of outcomes, a meta-analysis from 2018 (29) demonstrated that use of aortic endoclamping during minimally invasive surgery carried higher pooled risk of both aortic dissection $(\mathrm{OR}=3.88,95 \% \mathrm{CI}$ : 1.06-14.18; $\mathrm{P}=0.04)$ and conversion to sternotomy (OR $=3.07,5 \% \mathrm{CI}$ : $1.33-7.10 ; \mathrm{P}=0.009)$. However, the authors of that study clarify that when each study was analysed individually there was no increase in risk for both outcomes between endoclamping and external clamping patient groups. Thus, considering that the primary literature consists of nonrandomised cohorts, the authors suggest that with enough experience in using both techniques, other centres will be able to produce similar results between each technique (29).

Some surgeons report performing MIMVS surgery without cross clamping on the beating vented heart, or with inducing ventricular fibrillation; however, this approach increases the risk of air embolism and is generally reserved for more challenging or redo cases (9). The risk can be reduced by flooding the operative field with carbon dioxide, having the patient in the Trendelenberg position, and keeping the left ventricle empty and arterial pressure high on CPB (9).

\section{Myocardial protection}

In minimally invasive surgery, both anterograde and retrograde cardioplegia may be used (9). For anterograde cardioplegia, if using an external clamp, the aortic root may be cannulated directly. Cardioplegia solution can alternatively be delivered through the endoclamp if this is being used.

Retrograde cardioplegia is also used by some surgeons. It can be delivered through either a directly placed coronary sinus cannula, or alternatively through a percutaneous coronary sinus catheter placed by an anaesthetist through the internal jugular vein $(9,27,28)$.

The right mini-thoracotomy approach also makes topical cooling of the heart difficult to achieve. Therefore, systemic cooling may be used as an alternative (9). Longer acting cardioplegic solutions such as Del Nido or Custodiol® cardioplegia $(30,31)$ may also be employed. Indeed, singledose administration of Del Nido cardioplegia has been shown to provide equivalent myocardial protection as standard blood cardioplegia in minimally invasive aortic valve surgery (32), and in some cases may even be superior in terms of reducing myocardial injury (33). However, any beneficial effect may be offset by increased rewarming of the myocardium due to longer periods between cardioplegia solution delivery, and caution must be exercised when considering single-dose cardioplegia in high risk procedures or procedures with prolonged cross clamp times $(9,34)$.

\section{Surgical procedure}

Once CPB has been established, aorta cross-clamped and cardioplegia delivered, attention can be directed to accessing the mitral valve. This is achieved through dissecting Sondergaard's groove and performing a left atriotomy. An atrial retractor is used to display the mitral valve. This is usually placed through a small incision usually in the $3^{\text {rd }}$ or $4^{\text {th }}$ intercostal space just lateral to the right internal mammary vessels. As visualisation is optimized, the mitral valve can be assessed as normal, and repair or replacement performed. A variety of instruments have been developed to facilitate MIMVS, some adapted from VATS surgery. For example, the CorKnot ${ }^{\circledR}$ device (LSI Solutions, USA) which significantly reduces the time taken for knot tying with knot pushers, through the mini-thoracotomy incision.

Unsurprisingly, adopting this approach involves reduced dexterity due to the confined spaces necessitating the use of long shafted instruments $(3,18)$. Additionally, the subvalvular apparatus can be harder to visualise adequately in this approach, however, with increasing experience with use of the videoscope, excellent video-guided techniques can be carried out on the sub-valvular apparatus. Relating to body habitus, space or vision may be inadequate in either obese patients or patients with a smaller thorax $(18,35)$.

In general, mitral valve procedure can be mostly performed using minimally invasive approaches and these include both resection and non-resection techniques. Use of GoreTex neochords both as simple chords or loops, has become increasingly popular in minimally invasive surgery to avoid resection and maintain a sound physiological repair of the mitral valve (Figure 3).

\section{Pacing wires}

This is usually performed on the arrested heart to facilitate 


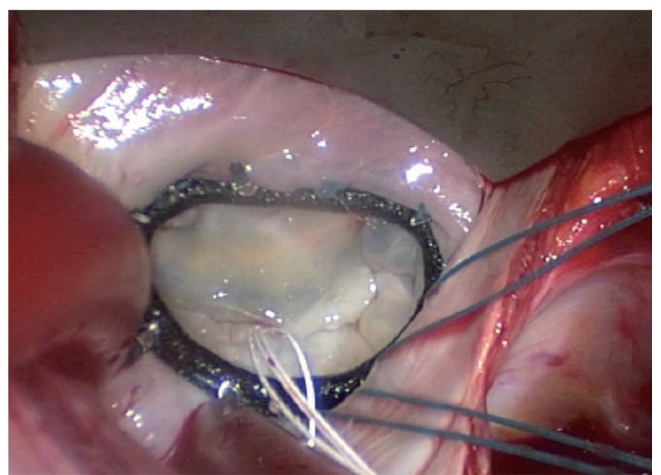

Figure 3 View of the mitral valve during minimally invasive mitral valve surgery following repair.

placement. We prefer to use bipolar right ventricular pacing wires applied to the anterior or inferior surfaces of the RV. Atrial wires can also be placed if necessary. The wires are brought up through the retractor pole puncture site in the $3^{\text {rd }}$ or $4^{\text {th }}$ intercostal space.

Alternatively, other approaches to insert pacing wires have been adopted by some that include transvenous pacing.

\section{Postoperative complications}

Patients will experience the range of complications typically observed following cardiac surgery. However, the mini-thoracotomy incision and approach presents some additional complications:

\section{Lung injury}

Lung injury may occur especially in the presence of pleural adhesions. This injury may arise due to mechanical trauma, and thermal or electrical damage due to use of diathermy. Any substantial injury should be exceptional.

There have been reports of cases of unilateral pulmonary oedema. Systemic hypothermia and maintenance of adequate arterial pressures have been suggested as mitigation strategies in dealing with this issue $(9,36)$. This is usually a major complication that may necessitate the temporary use of extracorporeal membrane oxygenation for support and is associated with significant mortality and morbidity (37).

\section{Postoperative pain}

Thoracotomy incisions may be associated with greater pain than a sternotomy. Pain control strategies intraoperatively include minimising chest wall trauma by limiting the size of incisions and degree of retraction, or avoiding rib spreading in some cases where feasible. Smaller sized drains can be used to further reduce compression of the intercostal nerves. Intercostal and extrapleural nerve blocks can also be utilised intraoperatively, and postoperatively if significant pain is experienced. Cryoablation (CryoICE, Atricure) has also been utilised in an attempt to minimise the pain in the perioperative period and enhance a rapid recovery $(38,39)$.

\section{Introducing MIMVS as a new technique}

When considering developing a MIMVS programme, as for any new technique, a team approach to the introduction of the programme is essential. It is important to engage all members of the multidisciplinary team-including anaesthetists and surgical nurses. It is valuable to visit as a team an expert centre, in order to gain familiarity with the technique. It is important to identify a proctor to facilitate introduction of the programme in the new centre. Clinical governance should be included as an essential component of the programme's introduction.

\section{Comparison of the mini right thoracotomy approach vs. sternotomy}

With the right mini thoracotomy approach, there is an obvious improvement in cosmesis, compared with midline incisions $(8,10,23)$ (Figure 4$)$. In addition to the improvements in cosmesis over conventional surgery, MIMVS patients also report increased satisfaction in terms of feeling ready to return to work, normal activity and improvements in subjective feeling (4). In terms of outcomes, a recently published meta-analysis by Moscarelli et al. included 18 studies with a cumulative 1,905 patients examining several outcome measures that include: recurrence of moderate-severe MR, need for reoperation after either MIMVS or sternotomy. The study reported no significant differences between minimally invasive and sternotomy approaches in terms of recurrent MR or redo operation rates $(1.7 \%$ vs. $1.3 \%$, respectively, $\mathrm{P}=0.22)$, failed repair rates $(1.6 \%$ vs. $3 \%$, respectively, $\mathrm{P}=0.66)$ or in hospital mortality ( $1 \%$ vs. $1.3 \%$, respectively, $\mathrm{P}=0.6$ ) (13). Some of the important outcomes are summarised in Table 4. The only predictive risk factor for reaching the primary outcome of recurrence of MR, was increased age $(\mathrm{P}=0.02)(13)$. As expected, the MIMVS group was exposed to longer cross-clamp and CPB times compared to the sternotomy group (85.6 vs. 63.4 minutes cross clamp time, 129.2 vs. 97 minutes $\mathrm{CPB}$ time; $\mathrm{P}=0.01$ for both) (13). Interestingly, 
this analysis demonstrated no difference between low and high volume centres (defined as below or above 50 cases, respectively) in terms of reaching the primary outcome (13). Limitations of the Moscarelli et al. meta-analysis include the heterogeneity in surgical techniques between centres, along with the proportion of underlying pathophysiology of MV disease included in each study (13). Types of operations included ranged from resection/ chordal implantation, complete or open ring, or edge-to-edge

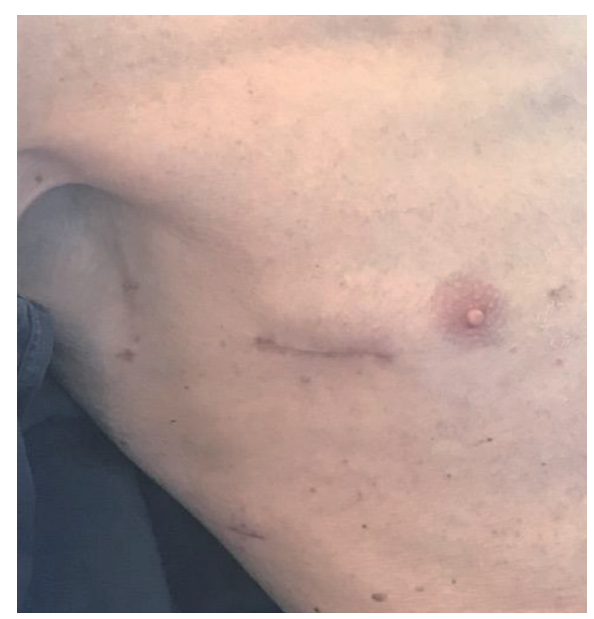

Figure 4 Example of the cosmetic result following minimally invasive mitral valve surgery. repair, among others (13).

A recent retrospective study investigated clinical outcomes in MIMVS $v s$. open sternotomy approaches, and reported 127 vs. 377 patients, respectively (40). Results were concordant with the meta-analysis above, with similar outcomes between MIMVS and sternotomy groups in rates of in-hospital mortality ( $0.8 \%$ vs. $0 \%$, respectively), surgical re-opening for bleeding ( $0.8 \%$ in both groups, $\mathrm{P}=1.0)$, failed repair $(12 \%$ vs. $13 \%, \mathrm{P}=0.829)$ and stroke occurrence ( $0.8 \%$ vs. $0.5 \%$, respectively, $\mathrm{P}=1.0$ ). Moreover, as reported in previous studies, $\mathrm{CPB}$ and cross clamp-times were significantly increased in the MIMVS group (CPB time 87 minutes $v s .76$ minutes; cross-clamp time 52 minutes $v$. 45 minutes; $\mathrm{P}<0.001$ for both) $(13,40)$. Despite the longer CPB times however, systemic inflammatory and cardiac injury markers were not elevated in the MIMVS group (40).

A case series from 2007 reported an average crossclamp time of three hours in minimally invasive repair of complex MV disease, the length of procedure highlighting the undoubtably complex nature of these operations (41). Therefore, some surgeons still prefer conventional sternotomy approaches especially in complex mitral disease due to the intrinsic difficulty of MV repair and long operation times associated with minimally invasive approaches $(13,41)$. Nevertheless, skilled operators with a lot of experience are indeed choosing minimally invasive

Table 4 Summary of important outcomes from the meta-analysis by Moscarelli et al. (13)

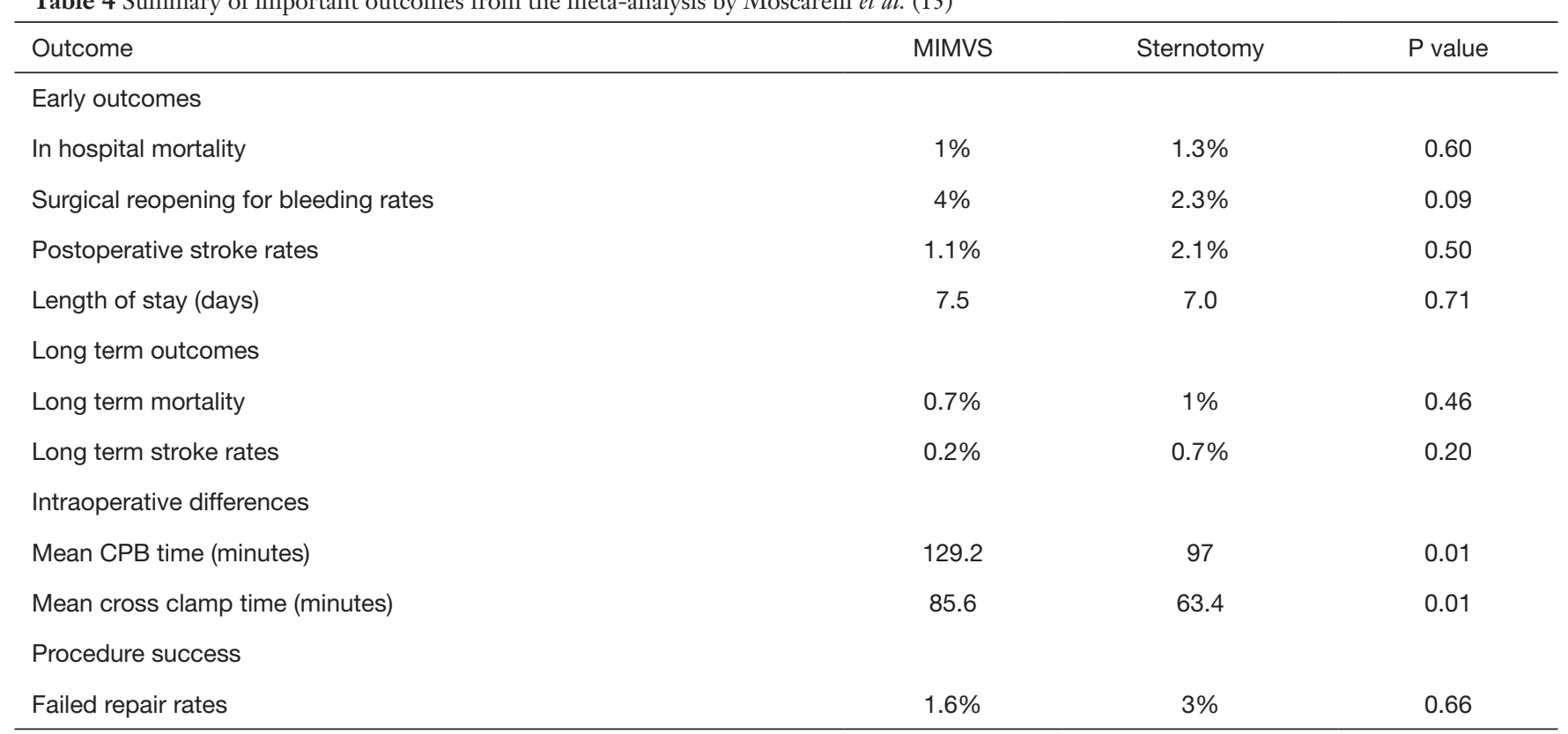

MIMVS, minimally invasive mitral valve surgery; CPB, cardiopulmonary bypass. 
approaches to address complex disease, as evidenced by 17 published studies which involve MIMVS being conducted on Barlow disease and 5 on bileaflet disease $(13,42)$. Furthermore there also reports of its use in the management of infective endocarditis (43).

Finally, the cost of the procedure must be considered, especially in the context of MIMVS requiring longer operative times and more specialised operative instruments (14). Despite these factors, numerous studies suggest that MIMVS may be cheaper than conventional sternotomy operations $(4,7,24,44-49)$. Cost savings appear to be driven by a combination of shorter hospital stays, reduced incidence of complications such as sepsis and reduced requirement of postoperative blood transfusion (50).

\section{Conclusions}

MIMVS is becoming increasingly widespread in cardiac surgical units globally. This is most commonly performed through a right anterolateral thoracotomy. Numerous studies have now shown favourable early and late clinical outcomes, in terms of in-hospital mortality, recurrence of mitral regurgitation or need for re-intervention. There is certainly a learning curve associated with this procedure (11) and there are challenges posed by the limited operative field including considerations relating to $\mathrm{CPB}$ and myocardial preservation. Despite some technical drawbacks such as prolonged $\mathrm{CPB}$ and cross clamp times, MIMVS remains equivalent to the standard sternotomy approach in terms of outcomes. Furthermore, MIMVS is associated with decreased postoperative hospital stays, reduced requirements of blood transfusion, cost savings and importantly, patient satisfaction. Therefore, although it is clear that patient selection is important, particularly early in a surgical programme, with experience complex repairs can be performed through a minimally invasive approach with excellent outcomes.

\section{Acknowledgments}

Funding: None.

\section{Footnote}

Provenance and Peer Review: This article was commissioned by the editorial office, Fournal of Thoracic Disease for the series "Minimally Invasive Cardiac Surgery". The article has undergone external peer review.
Reporting Checklist: The authors have completed the NARRATIVE REVIEW reporting checklist. Available at http://dx.doi.org/10.21037/jtd-20-2114

Peer Review File: Available at http://dx.doi.org/10.21037/jtd20-2114

Conflicts of Interest: All authors have completed the ICMJE uniform disclosure form (available at http://dx.doi. org/10.21037/jtd-20-2114). The series "Minimally Invasive Cardiac Surgery" was commissioned by the editorial office without any funding or sponsorship. Jason Ali and Yasir Abu-Omar served as the unpaid Guest Editors of the series. Jason Ali serves as an unpaid editorial board member of Fournal of Thoracic Disease from Oct 2019 to Sep 2021. The authors have no other conflicts of interest to declare.

Ethical Statement: the authors are accountable for all aspects of the work in ensuring that questions related to the accuracy or integrity of any part of the work are appropriately investigated and resolved.

Open Access Statement: This is an Open Access article distributed in accordance with the Creative Commons Attribution-NonCommercial-NoDerivs 4.0 International License (CC BY-NC-ND 4.0), which permits the noncommercial replication and distribution of the article with the strict proviso that no changes or edits are made and the original work is properly cited (including links to both the formal publication through the relevant DOI and the license). See: https://creativecommons.org/licenses/by-nc-nd/4.0/.

\section{References}

1. Ryan WH, Dewey TM, Mack MJ, et al. Mitral valve surgery using the classical "heartport" technique. J. Heart Valve Dis 2005;14:709-14.

2. Modi P, Hassan A, Chitwood WR. Minimally invasive mitral valve surgery: a systematic review and meta-analysis. Eur J Cardiothorac Surg 2008;34:943-52.

3. Navia JL, Cosgrove DM. Minimally invasive mitral valve operations. Ann Thorac Surg 1996;62:1542-4.

4. Cohn LH, Adams DH, Couper GS, et al. Minimally invasive cardiac valve surgery improves patient satisfaction while reducing costs of cardiac valve replacement and repair. Ann Surg 1997;226:421-6.

5. Carpentier A, Loulmet D, Carpentier A, et al. [Open heart 
operation under videosurgery and minithoracotomy. First case (mitral valvuloplasty) operated with success]. C R Acad Sci III 1996;319:219-23.

6. Chitwood WR, Elbeery JR, Moran JF. Minimally invasive mitral valve repair using transthoracic aortic occlusion. Ann Thorac Surg 1997;63:1477-9.

7. Chitwood WR Jr, Elbeery JR, Chapman WH, et al. Video-assisted minimally invasive mitral valve surgery: the "micro-mitral" operation. J Thorac Cardiovasc Surg 1997;113:413-4.

8. Van Praet KM, Stamm C, Sündermann SH, et al. Minimally invasive surgical mitral valve repair: State of the art review. Interv Cardiol 2018;13:14-9.

9. Barac YD, Glower DD. Port-Access Mitral Valve Surgery-An Evolution of Technique. Semin Thorac Cardiovasc Surg 2020;32:829-37.

10. Detter C, Boehm DH, Reichenspurner H. Minimally invasive valve surgery: Different techniques and approaches. Expert Rev Cardiovasc Ther 2004;2:239-51.

11. Holzhey DM, Seeburger J, Misfeld M, et al. Learning minimally invasive mitral valve surgery: A cumulative sum sequential probability analysis of 3895 operations from a single high-volume center. Circulation 2013;128:483-91.

12. Ramlawi B, Gammie JS. Mitral Valve Surgery: Current Minimally Invasive and Transcatheter Options. Methodist Debakey Cardiovasc J 2016;12:20-6.

13. Moscarelli M, Fattouch K, Gaudino M, et al. Minimal Access Versus Sternotomy for Complex Mitral Valve Repair: A Meta-Analysis. Ann Thorac Surg 2020;109:737-44.

14. Botta L, Cannata A, Bruschi G, et al. Minimally invasive approach for redo mitral valve surgery. J Thorac Dis 2013;5 Suppl 6:S686-93.

15. Moscarelli M, Casula R, Speziale G, et al. Can we use minimally invasive mitral valve surgery as a safe alternative to sternotomy in high-risk patients? Interact Cardiovasc Thorac Surg 2016;22:92-6.

16. Murzi M, Kallushi E, Tiwari KK, et al. Minimally invasive mitral valve surgery through right thoracotomy in patients with patent coronary artery bypass grafts. Interact Cardiovasc Thorac Surg 2009;9:29-32.

17. Glauber M, Karimov JH, Farneti PA, et al. Minimally invasive mitral valve surgery via right minithoracotomy. Multimed Man Cardiothorac Surg 2009;2009:mmcts.2008.003350.

18. Harky A, Chaplin G, Chan JSK, et al. The Future of Open Heart Surgery in the Era of Robotic and Minimal Surgical Interventions. Heart Lung Circ 2020;29:49-61.

19. Lehr EJ, Guy TS, Smith RL, et al. Minimally Invasive
Mitral Valve Surgery III: Training and Robotic-Assisted Approaches. Innovations (Phila) 2016;11:260-7.

20. Ailawadi G, Agnihotri AK, Mehall JR, et al. Minimally invasive mitral valve surgery i patient selection, evaluation, and planning. Innovations (Phila) 2016;11:243-50.

21. Wolfe JA, Malaisrie SC, Farivar RS, et al. Minimally Invasive Mitral Valve Surgery II: Surgical Technique and Postoperative Management. Innovations (Phila) 2016;11:251-9.

22. Reichenspurner H, Boehm D, Reichart B. Minimally invasive mitral valve surgery using three-dimensional video and robotic assistance. Semin Thorac Cardiovasc Surg 1999;11:235-43.

23. Reichenspurner H, Boehm DH, Gulbins H, et al. Threedimensional video and robot-assisted port-access mitral valve operation. Ann Thorac Surg 2000;69:1176-81; discussion 1181-2.

24. Chitwood WR, Nifong LW. Minimally Invasive Videloscopic Mitral Valve Surgery: The Current Role of Surgical Robotics. J Card Surg 2000;15:61-75.

25. Kypson AP, Nifong WW, Chitwood WR. Robotic mitral valve surgery. Semin Thorac Cardiovasc Surg 2003;15:121-9.

26. Barac YD, Glower DD. Minimally Invasive Mitral Repair: Direct Aortic Cannulation Via Right 2nd Intercostal Space. Innovations (Phila) 2018;13:315-7.

27. Stevens JH, Burdon TA, Peters WS, et al. Port-access coronary artery bypass grafting: A proposed surgical method. J Thorac Cardiovasc Surg 1996;111:567-73.

28. Fann JI, Pompili MF, Burdon TA, et al. Minimally invasive mitral valve surgery. Semin Thorac Cardiovasc Surg 1997;9:320-30.

29. Khan H, Hadjittofi C, Uzzaman M, et al. External aortic clamping versus endoaortic balloon occlusion in minimally inva-sive cardiac surgery: a systematic review and metaanalysis External aortic clamping versus endoaortic balloon occlusion in minimally invasive cardiac surgery: a systematic review and meta-analysis. Interact Cardiovasc Thorac Surg 2018;27:208-14.

30. Edelman JJB, Seco M, Dunne B, et al. Custodiol for myocardial protection and preservation: a systematic review. Ann. Cardiothorac. Surg 2013;2:717-28.

31. Sanetra K, Pawlak I, Cisowski M. Del Nido cardioplegia What is the current evidence? Kardiochir Torakochirurgia Pol 2018;15:114-8.

32. Ziazadeh D, Mater R, Himelhoch B, et al. Single-dose del Nido Cardioplegia in Minimally Invasive Aortic Valve Surgery. Semin Thorac Cardiovasc Surg 2017;29:471-6.

33. Ad N, Holmes SD, Massimiano PS, et al. The use 
of del Nido cardioplegia in adult cardiac surgery: A prospective randomized trial. J Thorac Cardiovasc Surg 2018;155:1011-8.

34. Siddiqi S, Blackstone EH, Bakaeen FG. Bretschneider and del Nido solutions: Are they safe for coronary artery bypass grafting? If so, how should we use them? J Card Surg 2018;33:229-34.

35. Nifong LW, Chitwood WR, Pappas PS, et al. Robotic mitral valve surgery: A United States multicenter trial. J Thorac Cardiovasc Surg 2005;129:1395-404.

36. Moss E, Halkos ME, Binongo JN, et al. Prevention of Unilateral Pulmonary Edema Complicating Robotic Mitral Valve Operations. Ann Thorac Surg 2017;103:98-104.

37. Renner J, Lorenzen U, Borzikowsky C, et al. Unilateral pulmonary oedema after minimally invasive mitral valve surgery: a single-centre experience. Eur J Cardiothorac Surg 2018;53:764-70.

38. Moore W, Kolnick D, Tan J, et al. CT Guided Percutaneous Cryoneurolysis for Post Thoracotomy Pain Syndrome. Early Experience and Effectiveness. Acad Radiol 2010;17:603-6.

39. Koethe Y, Mannes AJ, Wood BJ. Image-guided nerve cryoablation for post-thoracotomy pain syndrome. Cardiovasc Intervent Radiol 2014;37:843-6.

40. Jiang Q, Wang Z, Guo J, et al. Retrospective Comparison of Endoscopic Versus Open Procedure for Mitral Valve Disease. J Investig Surg 2020. [Epub ahead of print].

41. Anyanwu AC, Adams DH. Etiologic Classification of Degenerative Mitral Valve Disease: Barlow's Disease and Fibroelastic Deficiency. Semin Thorac Cardiovasc Surg 2007;19:90-6.

42. Percy E, Hirji SA, Yazdchi F, et al. Long-Term Outcomes

Cite this article as: Abu-Omar Y, Fazmin IT, Ali JM, Pelletier MP. Minimally invasive mitral valve surgery. J Thorac Dis 2021;13(3):1960-1970. doi: 10.21037/jtd-20-2114 of Right Minithoracotomy Versus Hemisternotomy for Mitral Valve Repair. Innovations (Phila) 2020;15:74-80.

43. Mihos CG, Santana O, Pineda AM, et al. Right anterior minithoracotomy versus median sternotomy surgery for native mitral valve infective endocarditis. J Heart Valve Dis 2014;23:343-9.

44. Grossi EA, Goldman S, Wolfe JA, et al. Minithoracotomy for mitral valve repair improves inpatient and postdischarge economic savings. J Thorac Cardiovasc Surg 2014;148:2818-22.e223.

45. Iribarne A, Easterwood R, Russo MJ, et al. A minimally invasive approach is more cost-effective than a traditional sternotomy approach for mitral valve surgery. J. Thorac. Cardiovasc. Surg 2011;142:1507-14.

46. Iribarne A, Easterwood R, Russo MJ, et al. Comparative effectiveness of minimally invasive versus traditional sternotomy mitral valve surgery in elderly patients. J Thorac Cardiovasc Surg. 2012;143:S86-90.

47. Gersak B, Sostaric M, Kalisnik JM, et al. The preferable use of port access surgical technique for right and left atrial procedures. Heart Surg Forum 2005;8:E354-63.

48. Cosgrove DM, Sabik JF, Navia JL. Minimally invasive valve operations. Ann Thorac Surg 1998;65:1535-8; discussion 1538-9.

49. Downs EA, Johnston LE, LaPar DJ, et al. Minimally Invasive Mitral Valve Surgery Provides Excellent Outcomes Without Increased Cost: A Multi-Institutional Analysis. Ann Thorac Surg 2016;102:14-21.

50. Santana O, Larrauri-Reyes M, Zamora C, et al. Is a minimally invasive approach for mitral valve surgery more cost-effective than median sternotomy? Interact Cardiovasc Thorac Surg 2016;22:97-100. 